\title{
A CONSCIÊNCIA FÁLICA EXISTENCIAL, NA TEORIA LITERÁRIA DE D. H. LAWRENCE
}

HERIBERTO ARNS

"O magnífico Aqui e Agora da Vida na Carne é Nosso, por alqum tempo. Dancemos com êxtase que estamos vivos e vivos na Carne, e somos parte do Cosmos Vivente e Encornado." (I) D. H. L.

Billy Graham : constatando evidentes sintomas de decadência da civilização ocidental, opina que o mito da rebelião do homem do ocidente contra Deus e a sociedade é antes um mito de D. Juan que de Prometeu (2).

Embora a nossa época não seja mais apocalíptica que muitas outras da história humana, não há que negar que a atual sociedade sofre uma explosão hedonística sem precedentes na história. Surae daí o problema psicosocial de profundas implicações não só na jurisprudência, na conceitologia da delinquência, mas ainda na própria validade das premissas psicológicas em que se baseiam os conceitos tradicionais da conduta humana na área erótica. Formam-se novos pontos de vista substancialmente opostos em relação ao fenômeno sexual na área da educação, na conduta conjugal e extra conjugal, no cinema, no teatro, na literatura e na arte em geral. A década dos 60 já foi caracterizada como a década do "Sex-Dynamo", da preocupação orgásmica, da explosão e da exploração do sexo, do realismo erótico, do impacto hedônico, da pornografia.

(1) "The magnificent here and now of life in the flesh is ours, and ours for a time. We ought to dance with rapture that we should be alive and in the flesh, and part of the living, incarnate cosmos. "Portrait of a Genius, but" by Richard Aldington - W. Heinemann Ltd. - London - p. 354.

(2) B. G. chama otenção para a licenciosidade que dominava a república de Weimor e que deu lugar ao regime austero e brutal do nazismo bem como para a liberalização moral de países desenvolvidos como a Suécia e c U.S.A., em contraste com a austeridade que procuram imprimir em suc constituição social, a Uniäo Soviética, Cuba e China (Time 11 de julho de 1969). 
Estaríamos, de fato, diante de evidentes sintomas de decadência dos mais nobres meios de comunicaçāo humano que são as artes? Ou mesmo diante de uma decadência de nossas estruturas morais? Ou, eventualmente, diante de uma abertura para novos conceitos de conduta humana com implicações nas mais variadas áreas da ética e do estética? A questão começa a interessar os próprios estudiosos da teoria da literatura. No entanto, o problema é tão antigo como a própria filosofia da estética: a Arte e a Moral. Para Platão: o artista não podia ser considerado guardião do Estado Ideal; ao contrário, ferido, marcado pelo destino, portador da enfermidade que é a genialidade artística, seria êle um exilado da sociedade. Genialidade e anormalidade, enfermidade caminham juntos no mundo da arte. As grandes eras literárias e artísticas não deixaram de pagar o tributo da instabilidade moral pela riqueza da produção artística de seus gênios. Os nascimentos e renascimentos da arte sempre tiveram como "background" inspirador uma sociedade em luta pela sua sobrevivência, um homem ameaçado de caos, uma fase histórica que, apesar de grandes conquistas e talvez deslumbrâncias exteriores, já trazia, em forma latente, a idéia e o clima para a tragédia; e assim, sem dúvida, a literatura trágica do século $X X$. E nessa literatura ou arte trágica, o Eros desempenho sua função. Édipo de SOFOCLES e o HAMLET de Shakespeare tecem sua urdidura em tôrno dum núcleo erótico, de forma tão profunda que se realiza a expressōo de Santayana: "high art cancels lust". Está talvez aí o ponto nevrálgico da questão. Tôda Obra de Arte, com lêtra maiúscula, exige um núcleo existencial que pode ser encontrado nas mais reservadas como nas mais triviais ocorrências humanas. O que importa é a Consciência Artística. Daí a dificuldade de concluir-se da simples temática e mesmo da realidade exterior dos enrêdos para o valor moral duma obra artística. "Ulysses" de James Joyce, sofreu não apenas reserva da parte do meio puritano, mas sua publicação foi barrada nos Estados Unidos até 1933, tendo sido o caminho de seu reconhecimento uma verdadeira odisséia. Muitas outras obras tiveram que transpor com grande dificuldade, as barreiras da censura, de legiões de decência ou polícia de costumes. Um dos autores mais visados foi, sem dúvida, o autor de "Lady Chatterley's Lover", D. H. Lawrence. Autor de uma vasta literatura de agressivo teor erótico, represento $D$. H. Lowrence um dos escritores que, em quase tôdas as suas obras de ficção, se movimenta na área litigiosa entre o que uns consideram arte; outros, pornografia. O autor de "Lady Chatterley's Lover" fêz a sua própria defesa em artigos e ensaios que, se bem que por vêzes carentes de objetividade e fundamentação, despertam um especial interêsse nesta década de "new morality".

$E^{\prime}$ necessária e fundamental a distinção ética e estética na Criteriologia artística. Pornografia não é necessàriamente uma 
literatura imoral; ela é, antes de tudo, uma literatura antiestética, trivial, baixa, carente de beleza, segundo os critérios vigorantes no julgamento estético de uma obra de arte. Talvez seja por essa razão, que a experiência da Dinamarca se torna válida quando lá o relaxamento da censura fêz cair a demanda da litertura pornográfica de um modo alarmante para este gênero de comercio. A área litigiosa do ético e do estético, é objeto de diversos ensaios críticos de D. H. Lawrence. Poeta e novelista dos mais produtivos, não se dedicou especificamente à crítica e teoria literária nem à filosofia da estética. No entanto, escreveu prefácios e introduções para inúmeras obras suas e de colegas, têz apreciações em artigos, cartas que foram reunidas após a sua morte (1Y30) e foram publicadas seis anos após no volume "Phoenix". Desde então, o acêrvo crítico vem aumentando, incluindo-se ainda sua vasta correspondência, quase tôda escrita ao ensejo de algum fato literário. Na análise de sua obra, destacam-se dois aspectos evidentes: a justificação de sua perspectiva freudiana e a dialética que essa perspectiva originou no inelo ambiente em que imperavam ainda os standards morais do purıtanismo vitoriano. A novela "The Rainbow" (3) foi cassada pela policia dos costumes, em 1915, poucas semanas depois de sua publicaçao. U magistrado da Bow Street ordenou a sua imediata destruiçáo. Lesde então, sua luta contra os guardiaes da moral pública foi ininterrupta, culminando, poucos anos antes de sua morte, quando sua mais tamosa obra de ficção "Lady Chatterley's Lover" (4) foi proibida de circular tanto na Grä-Bretanha como na América.

\section{"PURITANISM AND THE ARTS" (5)}

Em carta de doze de abril de 1927, D. H. Lawrence escreve: Estou perplexo diante da sorte de minha novela "Lady Chatterley's Lover". Ela é o que o mundo chama de impróprio. Você sabe que ela realmente não é imprópria. Meu esfôrço constante é dirigido no sentido de tornar "the sex relation valid and precious, instead of shameful" (6).

(3) The Rainbow opresenta o conflito entre o espiritual e o sensual, a vida dos instintos e do espírito num romance de três gerações inglêsas. Os personagens estão à procura do nôvo conhecimento da eternidade no fluxo do tempo. Movimenta-se a novela experimental numo visão dualística da Vida. Na terceira geração porece realizar-se uma emancipação.

(4) Lady Chatterley's Lover - (1928) - Constance, a personagem central, abandona o marido, aristocrato que voltara mutilado de guerra, para realizar-se seguindo os instintos, sua consciência fálica, que considera núcleo profundo da personolidade humana (phallic consciousness").

(5) Selected Literary Criticism - D. H. Lowrence - HEB - 1967.

(6) Ibid. -23. 
A cinco de março do ano seguinte, D. H. Lawrence lamenta: "the expurgations" (7) que êle fôra obrigado a fazer. A 17 de março, doze dias após, D. H. Lawrence procura caracterizar sua novela denominando-o "a novel of the phallic consciousness" (8) e protestando contra a qualificação de "sex".

Esse argumento repete-se em correspondências sucessivas declarando, por exemplo, em carta de 28 de dezembro de 1928 a Lady O Morrell: nada me causa maior náusea que a promiscuidade de sexo... o que eu pretendo é: estabelecer um ajustamento na consciência para "the basic physical realities" (9).

Na sua introdução para "These Paintings", D. H. Lawrence procura esclarecer o princípio de seu critério ético-estético. Opinando sôbre a pobreza da arte "visual" na Inglaterra, D. H. Lawrence atribui a principal causa não à folta de sensibilidade estética do povo inglês, mas à atitude inglêsa diante da Vida. Para êle o "anglo-saxon" sofre da paralisia do medo (10).

Esse "old fear" tem suo origem no tempo do renascimento. Válido ou não no caso específico da atitude puritana inglêsa diante da arte, apresenta D. H. Lawrence o argumento freudiano da compensação pela inibição moral, originária duma atitude. senāo hostil, ao menos constrangida diante do naturalismo renascentista da exaltaçāo do corpo humano em artes plásticos e pictóricas. O próprio Shakespeare é considerado por $D . H$. Lawrence "morb with fear, fear of consequences" (11).

O século XVI introduziu o que êle qualifica de "a horror of sexual life" (12).

Dando ênfase a "the northern consciousness" estabelece um contraste entre o renoscimento inglês e o espírito clássico gregolatino. Compara, por exemplo, Édipo e Hamlet constatando que o "mortal coil" em Hamlet é todo sexual, enquanto em Édipo o temor não procede do sexo em si e culmina no terror diante do Destino. Existe, portanto, uma diferença essencial nas atitudes, na consciência, que D. H. Lawrence caracteriza de "spiritual-mental consciousness" e "instinctive-intuitive consciousness" (13), essa última, radical, física, sexual (14).

(7) lbid. - 23.

(8) lbid. - 24.

(9) HEB - 25.

(10) Poralysis of fear - HEB - 53.

(11) HEB - 53.

(12) HEB - 53.

(13) HEM - 53.

(14) Realizondo, à sua maneira, uma investigação histórica, estabelece um paralelo entre o horror do sexo e as doenças venéreas que acometeram a dinastia e a aristocracia inglêsa. 
Esse elemento de "terror-horror" aniquila, alija, conforme D. H. Lawrence, "the consciousness of man" levando a um colapso que atinge a própria sensibilidade e afeta a atitude psicosocial do indivíduo, tornando-o frio em suas relações (15).

E o homem, destituido da sensibilidade intuitiva, perde o senso para a beleza e já não vê a beleza, mas, estarrecido, apenas - cadáver da beleza (16).

Forma-se assim no biotipo histórico-artístico "anglo-saxon" uma aversão aos instintos, o que dá origem a uma moralidade tôda própria em relação ao corpo, principalmente na sua função procriativa. Acresce que o terror inconsciente diante do venéreo determina uma atitude hostil diante da função procriativa do corpo do homem e da mulher. Depois de exemplificar sua teoria, D. H. Lawrence estabelece um paralelo com a atitude francêsa que considera mais consentânea porque dá o devido lugar ao corpo, embora de um modo racionalizado criando um conceito fundamentalmente higiênico do sexo que influi por sua vez na concepção do amor, do casamento, alimentação, esporte, etc.

D. H. Lawrence foi um pintor. Não só gostava de pintar, mas ainda escrever sôbre pintura, discutir pintura e, da pintura partia muitas vêzes para novas teorias literárias. No seu ensaio "Morality and the Novel" êle procede desta maneira, considerando o fim primordial da arte: revelar a relação existente entre o homem e seu universo circunambiente numa perspectiva artística. A moralidade é o elemento de equilíbrio oscilante, instável, entre o artista e seu universo quando êle procura estabelecer uma outêntica relação, sobretudo quando invade o domínio inconsciente e o âmago de tôdas as emoções humanas. E' 0 "trembling centre of balance" (17.

O conceito de moralidade de D. H. Lawrence não admite um definido divisor de águas. É, como as suas obras, um produto de seu freudianismo. E. T. Jessie Chambers, uma das suas companheiras e sua biógrafa (18) descreve a angústia de $D$. $H$. Lawrence após a morte da mãe e reproduz no capítulo sôbre "Sons and Lovers" (19) uma confissão esclarecedora do autor e do homem, D. H. Lawrence:

(15 Intuitively we ore dead to one another, we have all gone cold. Ibid - 58 .

(16) Their deeper responses, down in the intuitive and instinctive body, are not touched. They cannot be, because they are dead. A dead intuitive body stands there and gazes at the corpse of beauty. Ibid - 59 .

(17) Ibid. - 110 .

(18) D. H. Lawrence - a personal record.

(19) Sons and Lovers (19-3 - Romance autobiográfico, numa interpretaçāo edípoca-freudiana, apresento o conflito da mãe frustada na vida conjugal e os anseios dos filhos adolescentes. 
- We waited some time longer, then Lawrence looked at me with intensity."

- "You know - I've always loved mother", he said in a strangled voice."

- "I know you have;" I replied.

- "I don't mean that;" he returned quickly. "I've loved her, like a lover. That's why I could never love you!" With that he silently gave me a draft of the poems he had just written: "The End", "The Bride", "The Virgin Mother".

Foi após a crise aqui descrita e o posterior casamento com Frieda que D. H. Lawrence começou a formular "his mystical phallus-worship" 20).

Como Freudiano, D. H. Lawrence faz convergir o destino de seus protagonistas para o "Sexual Mystery" e suas urdiduras para o "Sexual Fate" (21).

Prevalece o princípio de que, a salvação do homem está na solução de seu "sexual mystery" (22).

O Homem e sua realização bio-psicológica é a norma suprema de seu dinamismo ético, porque residem aí objeto e fim de sua conceitologia existencial literária (23).

$E^{\prime}$ aí que, em última análise, se devem procurar as categorias e os limites de sua criteriologia moral.

\section{PORNOGRAPHY AND OBSCENITY (24)}

D. H. Lawrence parte do princípio de que o que é pornografia para um, pode ser rasgo de genialidade para outro. Investiga a origem etimológica dos têrmos pornografia e obscenidade: pornografia, o que se escreve em relaçāo à prostituição ou o que pertence à prostituição. Obsceno o que não pode ser representado em cena. E conclui que em ambos os casos se torna difícil estabelecer um critério que depende do julgamento duma maioria. Hamlet, por exemplo, chocou profundamente os Puri-

(20) D. H. Lowrence - 184.

(21) Sexual Date - Ibid. - 22.

(22) "It is in man's sexual impulse, taken out of the mental consciousness and returned to the body and the blood where it belongs." - Ibid.

(23) $E^{\prime}$ a "Daseinsverfassung" que compreende, de um lado, a insegurança diante do Destino existencial sempre condicionado pelo complexismo freudiano; doutro lado, o escapismo, fuga-refúgio, quando liberdade e limitaçāo da realização da satisfaçāo do insofreguidāo humana disputam numa área indefinida mental-instintal. A tendêncio literário polar Lawrenciana se fixa num núcleo existencial sexual agápico-erótico. Confere, por exemplo, com o psicologismo existencialisto de Jaspers ("Freiheit und Begrenztheit ... Unsicherheit und Geborgenheitssehnsucht".

(24) The Portable D. H. Lowrence - Diana Trilling - The Vicking Press 1960. 
tanos Cromwellianos e hoje não choca mais ninguém. Peças de Aristófanes ainda podem chocar a platéia de hoje e não impressionaram os gregos. O homem é uma besta, sujeito a mudanças, e as palavras mudam seus sentidos na proporção em que muda o homem. A platéia é que decide o que pode ser cênico ou obscênico. "Sex appeal", na concepção naturalista de D. H. Lawrence, não é pornografia, mas uma necessidade psicológica (25).

Pornografia mesmo, pertence ao submundo social e não tem vez na sociedade, porque representa um insulto ao sexo e ao espírito humano.

Esta distinção se torna válida quando D. H. Lawrence aduz sua experiência, isto é, o que êle mesmo viu em matéria de comércio clandestino pornográfico, "que o fez chorar". O poder dessa pornografia que é "um insulto ao corpo humano", "à espécie humana", D. H. Lawrence considera uma catastrofe para a nossa civilização. Julga que nossa civilização supera tôdas as outras, mesmo a romana, neste terreno, porque nenhuma outra civilização como a nossa tem degradado o "sex into the underworld, and nudity to the W. C. 26).

Para êle, o problema da pornografia é um problema de "secrecy". Sem "secrecy there whould be no pornography (27).

Esta pornografia, seja ela veiculada pela moda, filme e teatro, é um estimulante "to the vice of self-abuse, onanism, masturbation" (28).

Como acabar com a pornografia de acôrdo com o pensamento de D. H. Lawrence? (29) "Away with the secret! No more secrecy! The only way to stop the terrible mental itch about sex is to come out quite simply and naturally into the open with it" (30).

A solução lawrenciana, do problema social da pornografia, não se afasta muito do ponto de vista atual da psicologia social: abertura para uma educação sexual espontânea e reverente; com-

(25) The right sort of sex stimulus is invaluable to human daily life. Without it the world grows grey. Ibid. - 653 .

(26) Ibid. - 654 .

(27) Ibid. - 655 .

(28) Ibid. - 557.

(29) Ibid. 662.

(30) Ibid. - 662

"...first, to fight the sentimental lie of purity and the dirty little secret wherever you meet it, inside yourself or in the world outside... Then secondly, in his adventure of self-consciousnes of something beyond him... and make a new world. If my life is merely to go on in a vicious circle of self-enclosure, mosturboting self-consciousness, it is worth nothing to me. - Ibid. 667. 
bate a tồdas as inibiçōes psicológicas pela educação para a liberdade.

Em carta a Curtis Brown, D. H. Lawrence escrevia, em defesa a todos os ataques que então sofria: eu creio na consciência fálica... (31).

Do contexto gerol dos conceitos emitidos nas cartas e nos ensaios citados podemos concluir que D. H. Lawrence, apesar de certas incongruências (32),

1. - considero suas novelas nāo pornográficas nem obscenas, isto é, não pertencentes ou dirigidas ao submundo socia!, mas, que se destinam à sociedade;

2. - são fálicas, isto é, partem duma consciência voltada para o sexo como uma função vital, fundamental, tendo em vista nao apenas seu aspecto fisico-sexual, mas psico-espiritual-sexual. Aliás, em suas novelas, D. H. Lawrence cresce na proporção em que, na expressāo de D. Trilling "L. grows even more certain then when the mental-consciousness replaces the blood-consciousness the outcome is always tragic and wasteful, and not olone in our personal lives but also in our social lives" 33). D. H. Lawrence justifica seu falicismo considerando o dinamismo sexual não em dimensāo instintal, mas como fôrça vital dum núcleo existencial.

3. - sua consciência fálica faz parte integrante de seu conceito, objeto e fim da arte: o Homem todo, integral e todo seu mundo cirumambiente;

4. - seu conceito ético é oscilante, mutóvel, evolutivo, naturalístico, situacional, existencial;

5. - seu conceito estético, agressivo, inovador, dinâmico;

6. - suas observações de caráter sociológico, penetrantes e surpreendentes, revolucionárias, considerando-se que as escreveu há cinco e mais décadas atrás;

7. - o sexo é não só o mistério do Homem, mas seu "Fate", o arquiteto mítico-fálico de sua realizaçāo. Para tanto, D. H. Lawrence combate o sexo tanto como mera função hedonística em voga na decadência das civilizações, quanto como fun-

(31) "believe in the phallic consciousness, os against the irritable cerebral consciousness we're afficted with: and anybody who calls my novel a dirty sexual novel is a liar. It's not even a sexual novel: it's a phallic. Sex is a thing that exists in the head, its reactions ore cerebral, and its processes mental. Whereas the phallic reality is worm and spontaneous... Ibid. Letters - 598.

(32) Critical Approaches to Literature - David Daiches - Longmans - pág. 371. Lawrence's social origin can be usefully investigated by those interested in his psychology, our the relevance of such investigation to an understanding of the way in which his imagination works in his novels is surely dubious - pág. 371.

(33) The Portable D. H. Lowrence - Introd. - pág. 23. 
ção procreativa idealizada como a compreendem formalmente as religiões.

Embora Lawrence tenha escrito frases como esta: "I am a profoundly religious man" (34) suas convicções nada têm a haver com o conceito da religião pròpriamente dita... "his only God is the god of sexual mystery, the god in man's own blood. . . (35).

$E^{\prime}$ que $D$. H. Lawrence foi, neste campo, antes de mais nada um poeta, um literato. Como tal, expressou idéias poéticas, isto é, sua grande intuição artística não dimensionou idéias e imagens, pelos esquemas desta ou daquela filosofia, dessa ou daquela ética, dessa ou daquela religião. No fundo, foi êle o que sempre quis ser: "Phoenix" o símbolo talismânico (36) que se alça de suas Próprias Cinzas para uma Nova Vida.

E sua mensagem, embora existencial-naturalística, apresenta a consciência fálica não como um elemento psico-catalético, mas como uma atitude vivencial afirmativa.

8. - Sua concepção existencial o coloca como ponto avançado nesta nossa fase de transformações psico-sociais. Nem por isso, no fundo e na essência, sua obra é desintegrante, porque, oo contrário da pseudo-cultura "hippie", aspira à vivência plena da vida pela libertação interior e exterior do Homem.

Literàriamente, D. H. Lawrence realizou seu alto intento Se êle, porém, conseguiu a resposta adequada no mundo leitor, e, se a repercussão social de suas novelas foi a que êle desejou, dificilmente poderá ser averiguado.

(34) Ibid. -7 .

(35) Ibid. -8 .

(36) Ibid. -7 . 